\title{
EDUCAÇÃO INFANTIL E EDUCAÇÃO ESPECIAL: ENTRE AS FRONTEIRAS DO FAYVOR E DO DIREITO DE TODOS ÀS CONDIÇÕES DE CIDADANIA
}

\author{
EDUCACIÓN INFANTIL Y EDUCACIÓN ESPECIAL: ENTRE LAS FRONTERAS DEL \\ FAVOR Y DEL DERECHO DE TODOS A LAS CONDICIONES DE CIUDADANÍA
}

CHILD EDUCATION AND SPECIAL EDUCATION: BETWEEN THE FRONTIERS OF FAVOR AND THE RIGHT OF EVERYONE TO THE CONDITIONS OF CITIZENSHIP

\author{
Lázara Cristina da SILVA ${ }^{1}$ \\ Fernanda Duarte Araújo SILVA ${ }^{2}$ \\ Wender FALEIRO ${ }^{3}$
}

RESUMO: Este texto pretende refletir sobre as fronteiras existentes entre favor e as conquistas rumo ao direito à educação pública de qualidade referenciada socialmente, focalizado na Educação Infantil de 2008 a 2018, decorrentes da Política de Educação Especial na perspectiva da Educação inclusiva. Pretendeu-se compreender como a educação especial, no contexto da educação inclusiva, vem se estabelecendo enquanto política educacional, na primeira etapa da educação básica, e identificar os princípios, conceitos e serviços da educação especial focalizados nesta etapa da educação básica. É resultado de estudo de natureza exploratória, bibliográfica. Compreendeu-se que há uma articulação dos princípios e conceitos da educação especial nos documentos e ações desenvolvidas pelo Estado na Educação Infantil. Destaca a institucionalização das parcerias público-privadas, como uma forma de retorno e manutenção do favor em detrimento do direito à educação de todos às condições de cidadania, sinal de alerta para os educadores.

PALAVRAS-CHAVE: Políticas de Educação Infantil. Políticas de educação especial.

Criança e o direito à educação.

RESUMEN: Este artículo pretende reflexionar sobre las fronteras existentes entre favor y las conquistas hacia el derecho a la educación pública de calidad referenciada socialmente, enfocada en la educación infantil de 2008 a 2018, derivadas de la Política de Educación Especial en la perspectiva de la Educación inclusiva. Se pretendió comprender a la educación especial, en el contexto de la educación inclusiva, se viene estableciendo como política educativa, en la primera etapa de la educación básica e identificar los principios,

\footnotetext{
${ }^{1}$ Universidade Federal de Uberlândia (UFU), Uberlândia - MG - Brasil. Professora Adjunto IV da Faculdade de Educação. Líder do Grupo de Pesquisa em Políticas e Práticas em Educação Especial e Inclusão - GEPEPES. ORCID: <https://orcid.org/0000-0002-4647-8785>. E-mail: lazara@ufu.br

${ }^{2}$ Universidade Federal de Uberlândia (UFU), Ituiutaba - MG - Brasil. Docente do Curso de Pedagogia da Faculdade de Educação (FACED/UFU). Membro do Núcleo de Educação Infantil, Alfabetização, Metodologia da Língua Portuguesa, Educação de Jovens e Adultos e Práticas Educativas (Neiape/FACED/UFU). ORCID: <https://orcid.org/0000-0003-2041-0608>. E-mail: fernandaduarte.facip@ gmail.com

${ }^{3}$ Universidade Federal de Catalão (UFCAT), Catalão - GO - Brasil. Professor adjunto do curso de Educação do Campo. Pesquisador do Grupo de Pesquisa em Políticas e Práticas em Educação Especial e Inclusão GEPEPES. ORCID: <https://orcid.org/0000-0001-6419-296X>. E-mail: wender.faleiro@gmail.com
} 
conceptos y servicios de la educación especial enfocados en esta etapa de la educación básica. Es el resultado de un estudio de naturaleza exploratoria, bibliográfica. Se comprendió que hay una articulación de los principios y conceptos de la educación especial en los documentos y acciones desarrolladas por el Estado en la educación infantil. Destaca la institucionalización de las alianzas público-privadas, como una forma de retorno y mantenimiento del favor en detrimento del derecho a la educación de todos a las condiciones de ciudadanía, señal de alerta para los educadores.

PALABRAS CLAVE: Políticas de educación infantil. Políticas de educación especial. Niño y el derecho a la educación.

ABSTRACT: This text intends to reflect on the existing boundaries between favor and the achievements towards the right to public education of socially referenced quality, focused on the education of children from 2008 to 2018, arising from the Special Education Policy from the perspective of Inclusive Education. It was intended to understand such as special education in the context of inclusive education, has been established as an educational policy in the first stage of basic education and to identify the principles, concepts and services of special education focused on this stage of basic education. It is the result of an exploratory, bibliographical study. It was understood that there is an articulation of the principles and concepts of special education in the documents and actions developed by the State in early childhood education. It emphasizes the institutionalization of public-private partnerships, as a way of returning and maintaining favor to the detriment of the right to education of all citizenship conditions, a warning signal for educators.

KEYWORDS: Child education policies. Special education policies. Children the right to education.

\section{Introdução}

Pensar a Educação Infantil continua sendo um desafio na contemporaneidade; aliada à educação especial, estes se ampliam, pois, no campo educacional as mudanças são muito lentas, envolvem aspectos financeiros que impactam na formação de profissionais, na organização das estruturas físicas, de recursos humanos e pedagógicos dos sistemas de ensino, além de requerer mudanças de atitudes e pensamentos. Assim, apesar de, no Brasil, desde 1988 ter se iniciado uma nova compreensão da educação, tomada, desde então, como direito de todos, não mais como privilégios de alguns grupos socialmente bem provisionados financeiramente, ainda prevalecem pensamentos e práticas excludentes, que pregam a manutenção de privilégios para os referidos grupos como naturais, logo, convencionais e de direito adquirido.

Aliás, pensamentos tradicionalistas e conservadores têm ganhado espaço na sociedade contemporânea, uma vez que estão sendo retomadas práticas de escravidão, higienização e 
cerceamento da liberdade de escolha das pessoas na condição de expressão e de mobilidade. Esta realidade reforça a necessidade de se fortalecer os discursos inclusivos, apesar de os mesmos atuarem a favor da manutenção do sistema político e econômico capitalista, representam conquistas importantes que precisam ser mantidas, como é o fato da educação ser considerada um direito social subjetivo, logo inalienável e intransferível.

Portanto, este texto pretende refletir sobre as fronteiras do favor e as conquistas rumo ao direito à educação pública de qualidade referenciada socialmente ${ }^{4}$, focalizado na Educação Infantil de 2008 a 2018, decorrentes da Política de Educação Especial na perspectiva da Educação inclusiva, em avaliação à sua primeira década de existência. Assim, trata-se de pensar o processo de escolarização do público da educação especial na etapa da Educação Infantil. Como a educação especial, no contexto da educação inclusiva, vem se estabelecendo enquanto política educacional, na primeira etapa da educação básica? Os princípios, conceitos e serviços da educação especial estão sendo focalizados nesta etapa da educação básica?

Pretende-se com estas reflexões contribuir com o avanço do debate da educação como direito de todos, independente das condições físicas, biológicas, cognitivas, afetivas, emocionais, étnicas, culturais, econômicas, etc.

\section{Educação como direito de todos: dos princípios da educação inclusiva, educação especial} e Educação Infantil como construções legais

O ordenamento jurídico brasileiro é considerado um dos mais completos no tocante à educação inclusiva, focada na escolarização do público da educação especial. Desde 1988, com a aprovação da Constituição Federal, se optou pelo paradigma educacional da inclusão, a partir do qual a educação é reconhecida como um direito subjetivo de todo cidadão brasileiro. Está opção parece simples, mas provoca uma modificação substancial no entendimento quanto aos processos de escolarização, principalmente, das crianças brasileiras, as quais passam a ter a obrigatoriedade de estarem matriculadas na escola.

No texto constitucional, no campo específico da educação, explicita todas as outras responsabilidades do Estado em relação à Educação Infantil, ou seja, o direito das crianças de matrícula em escola pública (art. 205), gratuita e de qualidade (art. 206, incisos IV e VI),

\footnotetext{
${ }^{4}$ Entende-se por educação de qualidade referenciada socialmente aquela que "o alcance do que se almeja como qualidade da educação se vinculam aos diferentes espaços, atores e processos formativos, em seus diferentes níveis, ciclos e modalidades educativas, bem como à trajetória histórico-cultural e ao projeto de nação que, ao estabelecer diretrizes e bases para o seu sistema educacional, indica o horizonte jurídico normativo em que a educação se efetiva ou não como direito social" (DOURADO, 2009, p. 2002-2003).
} 
igualdade de condições em relação às demais crianças para acesso, permanência e pleno aproveitamento das oportunidades de aprendizagem propiciadas (art. 206, inciso I), obrigatoriedade da oferta e do acesso à educação desde os 04 anos de idade, ao Atendimento Educacional Especializado, bem como o direito à creche, sendo que antes dos 04 anos este direito não vem adicionado à obrigatoriedade como ocorre depois desta idade (Art. 208, incisos I, III e IV). Logo, fica evidente que a materialidade desse direito encontra-se vinculado ao cumprimento do Estado com a garantia de uma experiência educativa com qualidade a todas as crianças na Educação Infantil.

A aprovação do Estatuto da Criança e do Adolescente, Lei nº 8.069/90, pode ser tomado como um segundo marco, que avançou substancialmente no tocante aos direitos e deveres da criança e do adolescente brasileiro, que refletiu na mudança de hábitos e conceitos referentes à infância e seus processos de desenvolvimento, inclusive, a escolarização. Assim, a máxima "lugar de criança e adolescente é na escola" surge e ganha espaço no campo legal e educacional.

A seguir, a lei nº. 93.94/96, Lei de Diretrizes e Bases da Educação Nacional (LDB), ao regulamentar e detalhar as conquistas da Constituição Federal de 2018, apresenta a Educação Infantil como a primeira etapa da Educação Básica. Este foi um marco de extrema relevância, pois ocorre o fortalecimento do reconhecimento da Educação Infantil enquanto espaço formativo de direito, superando o paradigma do favor, no qual as crianças menos favorecidas economicamente, logo socialmente, eram acolhidas em instituições de cunho filantrópico e/ou vinculados à Ação Social do Estado, como um serviço de apoio às famílias carentes para favorecer as condições de ingresso e permanência no trabalho de seus pais e/ou responsáveis. Nestes espaços as crianças eram cuidadas e protegidas, mas a preocupação central não estava vinculada à educação, ao aprimoramento das condições para seu desenvolvimento cognitivo, social e cultural. Soma-se a isto o fato de ser um reduto eleitoreiro, que promovia a troca de favores entre aqueles que necessitavam fazer uso do serviço e os que o ofereciam, como se este não fosse financiado pelos recursos públicos.

A LDB também evidencia o direito aos serviços da Educação Especial a todos da Educação Básica, no seu art. 4, inciso III: “[...] atendimento educacional especializado gratuito aos educandos com deficiência, transtorno os globais do desenvolvimento e altas habilidades ou superdotação, transversal a todos os níveis, etapas e modalidades, preferencialmente na rede regular de ensino" (BRASIL, 1996, p. 11), cujas vagas sejam o mais próximo às suas residências, conforme o inciso $\mathrm{X}$ do mesmo artigo. Ainda, destinam os 
arts. 29 a 31 espaço a esta etapa da educação, nos quais apresentam seus princípios, objetivos e organização.

Os quatro princípios da inclusão, o da democratização do ensino, aliado ao da universalização, a acessibilidade e a flexibilização, vão sendo construídos e fortalecidos de maneira que as especificidades dos grupos socialmente organizados e as individualidades de cada um são tomadas como indicadores para se organizar e ofertar a educação, que como ato intencional e planejado não pode ocorrer de forma aleatória e pouco organizada.

A LDB apresenta o conceito de educação especial no Art. 58, como uma “[...] modalidade de educação escolar oferecida preferencialmente na rede regular de ensino, para educandos com deficiência, transtornos globais do desenvolvimento e altas habilidades ou superdotação" (BRASIL, 1996, p. 41), para em seguida, nos seus parágrafos, de 1 a 3, definir que haverá oferta dos serviços de apoio, conforme a necessidade do estudante, que a organização e a oferta do AEE ocorrerá segundo as condições/necessidades específicas dos estudantes, ainda, que a definição da oferta da educação especial é um dever do estado, iniciando-se desde a faixa etária de zero anos de idade.

A apresentação do conceito de educação especial veio abrandar o entendimento de que esta havia sido substituída pela inclusão educacional. Assim, aqui explicita o conceito de inclusão adotado no campo legal e, neste texto, como o direito de todos à educação. Assim, o conceito de inclusão é mais amplo, envolvendo a todas as modalidades e etapas da educação, enquanto a educação especial é uma modalidade da educação, segundo a legislação, após a Política Nacional de Educação Especial na modalidade inclusiva, de natureza complementar e suplementar, devendo permear todas as demais modalidades e etapas da educação, destinada a atender as pessoas com deficiências, transtornos globais do desenvolvimento e altas habilidades/superdotação. Desta forma, fica explícito que as discussões sobre educação inclusiva envolvem a educação especial, que está contida na mesma, mas não a substitui. São complementares.

Como o foco deste artigo são as reflexões da Educação Infantil após a publicação do texto da Política de Educação Especial na Perspectiva da Educação Inclusiva de $2008^{5}$, suas contribuições nesta sua primeira década, a partir deste momento, passaremos a tratar deste assunto, tendo como marco o período de 2008 a 2018.

${ }^{5}$ Para os interessados em conhecer o referencial legal anterior a 2008, que não fora abordado neste artigo, o texto da Política Nacional de Educação Especial na Perspectiva da Educação Inclusiva o apresenta de forma detalhada. 
O texto da política oferece destaque à Educação Infantil, reforçando seu caráter básico elementar necessário para fundamentar o desenvolvimento global do ser estudante. Destaca a importância nessa etapa do desenvolvimento de ações que incorporem

[...] o lúdico, o acesso às formas diferenciadas de comunicação, a riqueza de estímulos nos aspectos físicos, emocionais, cognitivos, psicomotores e sociais e a convivência com as diferenças favorecem as relações interpessoais, o respeito e a valorização da criança (BRASIL, 2008, p. 12).

Ora, evidencia-se a preocupação em garantir às crianças público da educação especial o acesso a todas as condições de desenvolvimento presentes no currículo da Educação Infantil, de maneira que desde o nascimento, a educação especial, por meio de seus serviços, no ambiente educacional, poderá ir contribuindo com as condições de desenvolvimento da criança. Portanto, na faixa etária dos zero aos 03 anos, “[...] o atendimento educacional especializado se expressa por meio de serviços de estimulação precoce, que objetivam otimizar o processo de desenvolvimento e aprendizagem em interface com os serviços de saúde e assistência social" (BRASIL, 2008, p. 12).

Nesta, como em todas as etapas e modalidades da educação básica, o "[...] atendimento educacional especializado é organizado para apoiar o desenvolvimento dos estudantes, constituindo oferta obrigatória dos sistemas de ensino" (BRASIL, 2008, p. 12). Entretanto, mesmo se tratando da Educação Infantil, a política mantém a orientação para que o AEE ocorra em "[...] turno inverso ao da classe comum, na própria escola ou centro especializado que realize esse serviço educacional” (BRASIL, 2008, p.12), para evitar o retorno à ideia de que a educação especial é uma modalidade paralela ou mesmo substitutiva ao ensino regular. Ou seja, apesar de compreender que a Educação Infantil é uma etapa que acontece e/ou tende a ocorrer em tempo integral, pretende-se deixar claro e evidente que essa ideia, ainda defendida por grupos com interesses específicos, não tenha força para retornar à realidade brasileira.

Como forma de estabelecer uma política pública da educação especial na perspectiva da educação inclusiva, em 2008 foi publicado o Decreto $n^{\circ}$. 6.571/2008. Marco histórico, inclusive, pois veio regulamentar o AEE que já estava previsto em documentos da educação nacionais anteriores a 1988. Tratou do apoio da União aos sistemas de ensino para ampliar a oferta do AEE a estudantes público da educação especial e estabeleceu o seu financiamento no âmbito do Fundo Nacional de desenvolvimento da educação básica - Fundeb. Este decreto, ainda, estabelece o público da educação especial, que já havia sido apresentado no texto da 
Política Nacional de Educação Especial na Perspectiva da Educação Inclusiva. Em 2011, é revogado com a aprovação do Decreto $\mathrm{n}^{\circ}$. 11.611/11, cujos conceitos e compromissos são apenas ampliados.

Destaca-se que as mudanças ocorridas no decreto $\mathrm{n}^{\circ}$. 11.611/11, foram frutos das relações de forças entre os grupos que defendem a manutenção de instituições específicas da educação especial e aqueles que defendem suas modificações para atender a perspectiva da inclusão, na qual a educação é um direito de todos, não sendo moeda de troca, nem espaço de manutenção de condições que privilegiem aspectos clínicos terapêuticos em detrimento dos pedagógicos. Após a sua publicação, as instituições especializadas, desde que com projetos pedagógicos aprovados pela Diretoria de Políticas de Educação Especial do MEC, poderão receber recursos públicos e continuar prestando serviços educacionais ao público da educação especial.

Na sequência, o Plano Nacional de Educação de 2014 a 2011, Lei nº 13.005, de 25 de junho de 2014, na Meta 1 pretendia "universalizar, até 2016, a Educação Infantil na pré-escola para as crianças de 4 (quatro) a 5 (cinco) anos de idade e ampliar a oferta de Educação Infantil em creches de forma a atender, no mínimo, 50\% (cinquenta por cento) das crianças de até 3 (três) anos até o final da vigência deste PNE” (BRASIL, 2014, p. 6), situação não alcançada. Nas estratégias 1.5 trata da ampliação do regime de colaboração e do respeito às normas de acessibilidade, dentre outras, visando a melhoria da rede física das escolas públicas de Educação Infantil; na 1.6 indica a necessidade de avaliação das condições de oferta da Educação Infantil, e na 1.11 de forma direta, apresenta o compromisso em

[...] priorizar o acesso à educação infantil e fomentar a oferta do atendimento educacional especializado complementar e suplementar aos (às) alunos (as) com deficiência, transtornos globais do desenvolvimento e altas habilidades ou superdotação, assegurando a educação bilíngue para crianças surdas e a transversalidade da educação especial nessa etapa da educação básica (BRASIL, 2014, p.10).

Nesta meta se evidencia, além da universalização como princípio da educação inclusiva, logo da educação especial, outro importante princípio, o da acessibilidade. Este, para além do direito em ter acesso à escola, trata da

[...] possibilidade e condição de alcance para utilização, com segurança e autonomia, de espaços, mobiliários, equipamentos urbanos, edificações, transportes, informação e comunicação, inclusive seus sistemas e tecnologias, bem como de outros serviços e instalações abertos ao público, de uso público ou privados de uso coletivo, tanto na zona urbana como na 
rural, por pessoa com deficiência ou com mobilidade reduzida. (BRASIL, 2015, p. 2)

Assim, as preocupações precisam extrapolar as questões do espaço escolar relacionado à estrutura física para receber as crianças, há que se ocupar em garantir-lhes condições adequadas para seu desenvolvimento saudável, autônomo e independente, no tocante às questões comunicativas e de acesso à informação, para que desde a primeira infância sejam preservados e dinamizados os mais diversos potenciais de todas as crianças, independente de estas serem público da educação especial.

De maneira específica, o PNE de 2014 a 2024 apresenta o compromisso com a universalização para o público da educação especial na Meta 4, que além do acesso à educação básica também trata dos seus serviços nesta etapa de ensino. Na estratégia 4.7, trata da garantia de oferta de educação bilíngue para surdos, em Língua Brasileira de Sinais (Libras) como primeira língua e na modalidade escrita da Língua Portuguesa como segunda língua, desde a primeira infância em escolas e/ou classes bilíngues. Ou seja, o lugar de todas as crianças desde a primeira infância é na escola, local que lhes oferecerá atenção e estímulos adequados ao seu desenvolvimento.

É notório no documento a força do poder persuasivo dos grupos organizados, que encontram brechas para fazer valer seus interesses específicos: denominados de cunho filantrópico, comunitário e confessional, apresentados sem fins lucrativos, mas que na realidade possuem muitas formas alternativas de se beneficiarem, inclusive economicamente, destes recursos. Trata-se das parcerias público-privadas previstas nas metas 4.17, 1.8 e 1.19, que focalizam as possibilidade de estabelecimento de parcerias para ampliar: a) "as condições de apoio ao atendimento escolar integral" aos estudantes público da educação especial; b) "a oferta de formação continuada e a produção de material didático acessível, assim como, os serviços de acessibilidade necessários ao seu pleno acesso, participação e aprendizagem" e "favorecer a participação das famílias e da sociedade na construção do sistema educacional inclusivo" (BRASIL, 2011, p. 5-6).

A presença destas metas pode contribuir com o retorno da questão do favor, que estava em suspenso na Educação Infantil. Com o estabelecimento destas parcerias, o Estado transfere para os setores privilegiados da sociedade civil recursos públicos para que estes realizem parte de suas atribuições com a educação em suas diferente etapas e modalidades, inclusive a infantil. Nestes casos, as relações trabalhistas e de acesso à educação que estavam regulamentadas segundo os princípios da educação pública, voltam a ser dirigidas a interesses 
privados e de grupos específicos no poder. Assim, essas metas podem remeter à retrocessos, portanto, precisam ser monitoradas com cuidado.

Ainda, visando subsidiar os sistemas de ensino quanto aos aspectos apresentados, em 2015 foi aprovada a nota técnica n. 2, editada em conjunto entre as Secretarias de Educação Continuada, Alfabetização, Diversidade e Inclusão (SECADI) e Secretaria de Educação Básica, por meio das Diretoria de Políticas de Educação Especial (DPEE) e a Diretoria de Currículos e Educação Integral (DICEI), abordando as orientações para a organização e oferta do AEE na Educação Infantil. $O$ texto da nota apresenta o arcabouço legal que respalda a educação especial na perspectiva da educação inclusiva, os avanços que tais legislações significam. Aparece o destaque ao planejamento da instituição para receber estudantes da educação especial na Educação Infantil.

O planejamento institucional, expresso pelo Projeto Político Pedagógico (PPP) da escola, oferece espaço para se explorar outros dois princípios da educação inclusiva, a acessibilidade e a flexibilização curricular. O PPP da escola pode definir as condições de oferta do currículo, sua organização e tempos escolares, bem como os processos avaliativos. É um poderoso espaço político de atuação profissional (BRASIL, 2009, 2013). A flexibilização dos tempos escolares, das formas de organização do trabalho pedagógico

[...] As propostas pedagógicas da Educação Infantil das crianças filhas de agricultores familiares, extrativistas, pescadores artesanais, ribeirinhos, assentados e acampados da reforma agrária, quilombolas, caiçaras, povos da floresta, devem: I - reconhecer os modos próprios de vida no campo como fundamentais para a constituição da identidade das crianças moradoras em territórios rurais; II - ter vinculação inerente à realidade dessas populações, suas culturas, tradições e identidades, assim como a práticas ambientalmente sustentáveis; III - flexibilizar, se necessário, calendário, rotinas e atividades respeitando as diferenças quanto à atividade econômica dessas populações; IV - valorizar e evidenciar os saberes e o papel dessas populações na produção de conhecimentos sobre o mundo e sobre o ambiente natural; V prever a oferta de brinquedos e equipamentos que respeitem as características ambientais e socioculturais da comunidade (BRASIL, 2013, p. 99).

A nota Técnica 02/2015 destaca que o PPP da Escola precisa apresentar de forma clara como os serviços da educação especial estarão organizados para atingir seus objetivos e metas. Ainda, apresenta diversas atividades do professor do AEE, dentre elas a relacionada à Educação Infantil, que prevê o atendimento às crianças público da educação especial não restrito à sala de recursos multifuncionais, mas em todos os espaços da escola. Define que esses atendimentos ocorram no contexto da instituição educacional, requerendo do professor 
do AEE a atuação em diferentes ambientes, tais como: berçário, solário, parquinho, sala de recreação, refeitório, entre outros, onde as atividades comuns a todas as crianças são adequadas às suas necessidades específicas (BRASIL, 2015).

Entretanto, apesar de ocorrer em diferentes espaços não quer dizer que tais atividades sejam substitutivas às do currículo da fase da Educação Infantil. Este é um fundamento que precisa ser garantido, pois, caso contrário, no cotidiano escolar, a criança passa ser vinculada ao professor do AEE, deixando o professor da turma para os demais. Neste aspecto, há o fortalecimento das ações atribuídas ao professor do AEE relacionadas a "[...] articulação com os professores do ensino comum, visando à disponibilização de recursos de apoio necessários à participação e aprendizagem dos estudantes" (BRASIL, 2009, p. 3).

Segundo a Nota Técnica conjunta $n^{\circ}$. 02/2015, a principal atribuição do professor do AEE na Educação Infantil é “[...] identificar barreiras e implementar prática e recursos que possam eliminá-las, a fim de promover ou ampliar a participação da criança com deficiência em todos os espaços e atividades propostos no cotidiano escolar" (BRASIL, 2015, p. 4).

Alinhadas ao que dispõe as Diretrizes Curriculares Nacionais para a Educação Infantil (DCNEIs), as atividades pedagógicas e curriculares a serem desenvolvidas nas escolas de Educação Infantil precisam focar como eixos norteadores as interações e as brincadeiras, promovendo relacionamento e interações entre as crianças. No contexto da Educação Infantil a brincadeira assume papel primordial, por ser considerada um dos principais meios de expressão das crianças, favorecendo o desenvolvimento por meio de experiências com o mundo e com as pessoas. O brincar é uma atividade tomada como direito da criança, pois a coloca em contato com o mundo, propicia-lhe explorar a realidade, desenvolver a criatividade, a autonomia, a interatividade com os outros, enfim, potencializar todas as condições necessárias a seu desenvolvimento cognitivo, afetivo e emocional.

O currículo da Educação Infantil é concebido como um conjunto de práticas que buscam articular as experiências e os saberes das crianças com os conhecimentos que fazem parte do patrimônio cultural, artístico, científico e tecnológico. Tais práticas são efetivadas por meio de relações sociais que as crianças desde bem pequenas estabelecem com os professores e as outras crianças, e afetam a construção de suas identidades. (BRASIL, 2013, p. 86)

Quanto mais a criança interage com outras crianças e com brinquedos, mais ela amplia suas possibilidades de desenvolvimento. Assim, aquelas público da educação especial, quando convivem com crianças com condições e experiências bio-pisco-cognitivas 
diferenciadas daquelas que lhes são possíveis, ampliam as suas potencialidades de desenvolvimento cognitivo, cultural e social.

A criança, centro do planejamento curricular, é sujeito histórico e de direitos que se desenvolve nas interações, relações e práticas cotidianas a ela disponibilizadas e por ela estabelecidas com adultos e crianças de diferentes idades nos grupos e contextos culturais nos quais se insere. Nessas condições ela faz amizades, brinca com água ou terra, faz-de-conta, deseja, aprende, observa, conversa, experimenta, questiona, constrói sentidos sobre o mundo e suas identidades pessoal e coletiva, produzindo cultura (BRASIL, 2013, p. 86).

Considerando os dois eixos norteadores da Educação Infantil definidos nas DCNEIs, as interações e a brincadeira, foi organizado e aprovado em 2017 o documento da Base Nacional Curricular Comum (BNCC), que será trabalhada de maneira a assegurar à criança, no mínimo, seis direitos de aprendizagem e desenvolvimento: conviver, brincar, participar, explorar, expressar e conhecer-se. Tais direitos são organizados e explorados em forma de objetivos e ações considerando cinco campos de experiências, a serem trabalhados de forma articulada e contínua para promoverem condições de a criança aprender e se desenvolver, a saber: o eu, o outro e o nós; corpo, gestos e movimentos; traços, sons, cores e formas; escuta, fala, pensamento e imaginação; espaços, tempos, quantidades, relações e transformações (BRASIL, 2017). Apesar de polêmico, pela forma como foi conduzido na última etapa de elaboração e aprovação, o documento, nesta etapa da educação, não apresenta grandes problemas.

A educação é uma ação intencional, que demanda

[...] a organização e proposição, pelo educador, de experiências que permitam às crianças conhecer a si e ao outro e de conhecer e compreender as relações com a natureza, com a cultura e com a produção científica, que se traduzem nas práticas de cuidados pessoais (alimentar-se, vestir-se, higienizar-se), nas brincadeiras, nas experimentações com materiais variados, na aproximação com a literatura e no encontro com as pessoas (BRASIL, 2017, p.39)

Assim, é inerente à função do professor da Educação Infantil as atividades relacionadas às ações no tocante a refletir, selecionar, organizar, planejar, mediar e monitorar o conjunto das práticas e interações educacionais previstas no currículo, bem como, ao efetivá-las, garantir a pluralidade de situações que promovam o desenvolvimento pleno das crianças. Portanto, esses direitos não dependem de quais conjuntos de crianças o trabalho será realizado, de suas condições biopsicossociais e culturais. São direitos. O que é possível 
flexibilizar são as formas e a organização do trabalho docente para tornar possível a articulação e o planejamento conjunto entre os profissionais envolvidos no fazer pedagógico dessas crianças. Por conseguinte, aqueles que atuam para manter o direito daquelas crianças público da educação especial precisam possuir espaço para o diálogo com os demais professores e profissionais da escola, bem como com a família, visando sempre a criação de condições reais para o desenvolvimento da criança sem violar seu direito à aprendizagem e ao desenvolvimento integral.

Como destacado desde o início do texto, as questões para a garantia desse direito voltam-se sempre para os aspectos financeiros. São inúmeras justificativas pautadas nas dificuldades econômicas, para tanto, foram criadas medidas e programas governamentais visando reduzir as intercorrências relacionadas a esta questão. As crianças público da educação Especial são contadas duplamente para efeitos de repasses econômicos via Fundeb, independente do espaço onde ocorra o vínculo para os serviços da educação especial, na escola e/ou em instituições especializadas (BRASIL, 2008). Foram lançados programas para aquisição de utensílios e materiais pedagógicos e estruturais acessíveis, indicados para as necessidades específicas de cada grupo de estudantes público da educação especial, programas para formação dos profissionais, programas para acessibilidade de livros didáticos e infantis, dentre outros.

Ainda, existe um grande quantitativo de ações a serem realizadas, mas fazer um retrospecto histórico nos permite identificar um grande avanço, embora também se reconheça a necessidade de se ampliar as atividades a serem realizadas. Foram dez anos de muito trabalho.

\section{Considerações finais}

Pretendeu-se identificar e refletir como a educação especial, no contexto da educação inclusiva, foi se estabelecendo enquanto política educacional, na primeira etapa da educação básica. No decorrer do artigo, foi possível compreender que de forma persistente e articulada, a educação especial foi se estabelecendo como um conjunto de ações organizadas nas diferentes áreas e etapas da educação. Todos os documentos nacionais reconhecem a educação especial com sua dimensão transversal, complementar e suplementar. Os princípios, conceitos e serviços da educação especial estão sendo focalizados na Educação Infantil, como nas demais etapas e modalidades. 
Foi possível compreender que o paradigma da inclusão foi assumido nacionalmente. No entanto, é necessário destacar que este tem se expandido e fortalecido, não como desdobramento das lutas sociais dos grupos considerados minoritários, tais como os negros, indígenas, pobres e aqueles vinculados à educação especial. Houve um processo de ressignificação desses desejos e necessidades, uma vez que, dentro do sistema, são formados segundo seus princípios, tornam-se presas produtoras e consumidoras, logo partícipes do sistema.

Chama atenção para o fato de as parcerias público-privadas estarem presente nos documentos como algo necessário, pois o Estado não consegue cobrir as demandas específicas. No senso comum, tem-se que as organizações da Sociedade Civil (OSCs), são instituições de cunho filantrópico, comunitário e confessional, logo não possuem interesses escusos. Entretanto, na contemporaneidade, em conformidade com o sistema político e econômico capitalista neoliberal, estas atuam no sentido de fortalecer o setor privado, precarizar as condições de trabalho dos docentes, oferecer serviços com custos para o Estado no mesmo patamar, mas para a população com investimentos diferenciados. Estas transferências de responsabilidade do setor público para o terceiro setor são mecanismos de manutenção das estruturas de exploração e favorecimento dos "eternos" donos do poder político econômico, que além de obter benefícios econômicos ainda mantêm as pessoas reféns de suas ações político partidárias. As redes de educação municipais são os focos dessas OSCs, que oferecem seus serviços, adentram o espaço escolar e direcionam os caminhos das famílias carentes. As crianças são apenas a porta de entrada na mina.

Quando mais cedo a educação e a formação para o trabalho iniciar, mais adequados serão os resultados do processo. Para além dessa crítica, a política Nacional de Educação Especial na perspectiva da Educação Inclusiva apesar de tímida e sufocada pela pressão de grupos fortes com interesses específicos, representou avanços na educação brasileira.

Diante dos avanços apresentados, cabe aos educadores e cidadãos em geral acompanhar os processos de terceirização, lutar para que as conquistas sociais não percam seus espaços para ações revestidas de caráter inovador, tecnológico e compromissadas com o social. A luta continua...

\section{REFERÊNCIAS}


BRASIL. Constituição da República Federativa do Brasil. Brasília, DF: Senado Federal, 1988. Disponível em:

http://www.planalto.gov.br/ccivil_03/constituicao/constituicaocompilado.htm. Acesso em: 04 ago. 2018.

BRASIL. Lei n ${ }^{\circ} 8.069$, de 13 de julho de 1990. Dispõe sobre o Estatuto da Criança e do Adolescente e dá outras providências. Diário Oficial da União, Brasília, 16 de julho de 1990. Disponível em: http://www.planalto.gov.br/ccivil_03/leis/L8069.htm. Acesso em: 23 mar. 2017

BRASIL, Lei 9394/96, Lei de Diretrizes e Bases da Educação Nacional. Disponível http://www2.senado.leg.br/bdsf/bitstream/handle/id/529732/lei_de_diretrizes_e_bases_1ed.pd f. Acesso: 04 ago. 2018

BRASIL, MEC/SECADI/DPEE. Política Nacional de Educação Especial na Perspectiva da Educação Inclusiva. 2008. Disponível em:

http://portal.mec.gov.br/index.php?option=com_docman\&view=download\&alias=16690politica-nacional-de-educacao-especial-na-perspectiva-da-educacao-inclusiva05122014\&Itemid=30192 Acesso: 04 ago. 2018.

BRASIL, MEC/SECADI/DPEE. Orientações para a organização e oferta do Atendimento Educacional Especializado na Educação Infantil. 2009. Disponível em: http://portal.mec.gov.br/index.php?option=com_docman\&view=download\&alias=17237secadi-documento-subsidiario-2015\&Itemid=30192. Acesso. 04 ago. 2018.

BRASIL, CNE. Diretrizes Curriculares Nacionais Gerais da Educação Básica. Ministério da Educação. Secretária de Educação Básica. Diretoria de Currículos e Educação Integral. Brasília: MEC, SEB, DICEI, 2013. Disponível em: http://portal.mec.gov.br/docman/julho2013-pdf/13677-diretrizes-educacao-basica-2013-pdf/file. Acesso: 04 ago. 2018.

BRASIL. Lei no 13.005, de 25 de junho de 2014. Aprova o Plano Nacional de Educação PNE e dá outras providências. Diário Oficial da União, Brasília, 26 de junho de 2014. Disponível em: http://www.planalto.gov.br/ccivil_03/_ato2011-2014/2014/lei/113005.htm. Acesso em: 23 mar. 2017

BRASIL, MEC/SECADI/DPEE/SEB/DICEI. Nota técnica conjunta no 02/2015. Disponível em: http://www.observatoriodopne.org.br/saiba-mais/nota-tecnica-conjunta-n-02-orientacoespara-a-organizacao-e-oferta-do-aee-na-educacao-infantil. Acesso em: 04 ago. 2018

BRASIL, Câmara dos Deputados. Lei no 13.146, de 6 de julho de 2015. Institui a Lei Brasileira de Inclusão da Pessoa com Deficiência (Estatuto da Pessoa com Deficiência). Disponivel em: http://www2.camara.leg.br/legin/fed/lei/2015/lei-13146-6-julho-2015781174-normaatualizada-pl.pdf. Acesso: 04 ago. 2018.

BRASIL, MEC. Base Nacional Comum Curricular. 2018. Disponível em http://basenacionalcomum.mec.gov.br/abase/\#infantil/os-objetivos-de-aprendizagem-edesenvolvimento-para-a-educacao-infantil. Acesso: 04 ago. 2018. 
DOURADO, L. F.; OLIVEIRA, J. F. de. A QUALIDADE DA EDUCAÇÃO:

PERSPECTIVAS E DESAFIOS. Cad. Cedes, Campinas vol. 29, n. 78, p. 201-215, maio/ago. 2009.

\section{Como referenciar este artigo}

SILVA, Lázara Cristina da.; SILVA, Fernanda Duarte Araújo.; FALEIRO, Wender. Educação infantil e educação especial: entre as fronteiras do favor e do direito de todos às condições de cidadania. Revista Ibero-Americana de Estudos em Educação, Araraquara, v. 14, n. esp. 1, p. 702-716, abr., 2019. E-ISSN: 1982-5587. DOI: 10.21723/riaee.v14iesp.1.12200

Submetido em: 06/08/2018

Aprovado em: 21/09/2018 